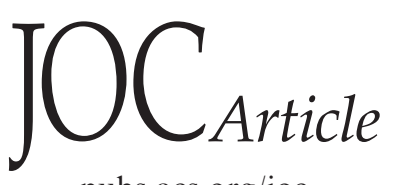

pubs.acs.org/joc

\title{
Solute Descriptors for Phenoxide Anions and Their Use To Establish Correlations of Rates of Reaction of Anions with Iodomethane
}

\author{
Michael H. Abraham*, ${ }^{*}$ and William E. Acree, Jr.* \\ ${ }^{\dagger}$ Department of Chemistry, University College London, 20 Gordon Street, London WC1H 0AJ, U.K., and \\ ${ }^{*}$ Department of Chemistry, 1155 Union Circle Drive no. 305070, University of North Texas, Denton, Texas \\ 76203-5017
}

m.h.abraham@ucl.ac.uk

Received February 16, 2010

\begin{tabular}{|cl|}
\hline ArOH & \multicolumn{1}{c|}{ ArO } \\
Strong H-bond acid & No H-bond acidity \\
Weak H-bond base & Strong H-bond base \\
Weakly dipolar & Strongly dipolar \\
\hline
\end{tabular}

Partition coefficients from water to organic solvents for phenoxide anions have been obtained using a method based on the variation of $\mathrm{p} K_{\mathrm{a}}$ of phenols with solvent. From these partition coefficients, the Abraham descriptors for phenoxide anions, on the same scale as descriptors for neutral molecules, have been obtained. Equations have been constructed for the prediction of descriptors, and values of the Abraham descriptors $\mathbf{E}, \mathbf{S}, \mathbf{A}$ (equal to zero for the phenoxide anions we have studied), $\mathbf{B}, \mathbf{V}$, and $\mathbf{J}^{-}$have been determined or estimated for some 60 substituted phenoxide anions. These anions are characterized by very large values of the dipolarity/polarizability descriptor $\mathbf{S}$ and the hydrogen bond basicity descriptor $\mathbf{B}$. In order to show the utility of the obtained phenoxide descriptors, we demonstrate that they can be combined with descriptors for carboxylate anions and permanent anions to yield equations for the Finkelstein reaction of anions with iodomethane in methanol, $N, N$-dimethylformamide, and water.

\section{Introduction}

Previously we have set out water to solvent partitions coefficients, $P$, for carboxylate anions and protonated amines and have used these partition coefficients, as $\log P$, to obtain solvation descriptors for the above ionic species. ${ }^{1}$ The solvation descriptors were on the same scales as those for neutral species, so that both neutral and ionic species could be included in the same equations. Two methods were used to obtain the required $\log P$ values for carboxylate anions. The classical method is from solubilities of ionic species in water and a given solvent, with due regard to ion association and activity coefficients. The second method makes use of the ionization equilibria, eqs 1 and 2 , in water and a given solvent.

$$
\begin{gathered}
\mathrm{HA}(\mathrm{aq})=\mathrm{H}^{+}(\mathrm{aq})+\mathrm{A}^{-}(\mathrm{aq}) \\
\mathrm{HA}(\mathrm{s})=\mathrm{H}^{+}(\mathrm{s})+\mathrm{A}^{-}(\mathrm{s})
\end{gathered}
$$

Then for transfer from water to the other phase, $\log P\left(\mathrm{~A}^{-}\right)$is given by eq 3 :

$\log P\left(\mathrm{~A}^{-}\right)=\log P(\mathrm{HA})-\log P\left(\mathrm{H}^{+}\right)+\mathrm{p} K_{\mathrm{a}}(\mathrm{aq})-\mathrm{p} K_{\mathrm{a}}(\mathrm{s})$

(1) Abraham, M. H.; Acree, W. E., Jr. J. Org. Chem. 2010, 75, 1006-1015.
In eq 3 , it is essential to specify the ionic convention for the partition of $\mathrm{H}^{+}$between water and the solvent because this will determine the ionic convention for the partition of the anion $\mathrm{A}^{-}$. We used the convention that all $\log P$ values for ions are based on $\log P$ for $\mathrm{Ph}_{4} \mathrm{As}^{+}$or $\mathrm{Ph}_{4} \mathrm{P}^{+}=\log P$ for $\mathrm{Ph}_{4} \mathrm{~B}^{-1}$, and this is the convention we shall use for phenoxide anions. Pliego and Riveros ${ }^{2}$ have used similar equations to determine solvation Gibbs energies of anions and cations in dimethylsulfoxide (DMSO).

For the correlation and prediction of processes involving neutral solutes, we used the linear free energy relationship:

$$
\mathrm{SP}=c+e \mathbf{E}+s \mathbf{S}+a \mathbf{A}+b \mathbf{B}+v \mathbf{V}
$$

Here, the dependent variable SP is a property of a series of solutes, for example, SP might be $\log P$ for partition from water to methanol. The independent variables in eq 4 are solute descriptors defined exactly as before. ${ }^{3,4}$ Equation 4 is a well-tested equation that has been used to

(2) Pliego, J. R., Jr.; Riveros, J. M. Phys. Chem. Chem. Phys. 2002, 4, 1622-1627.

(3) Abraham, M. H. Chem. Soc. Rev. 1993, 22, 73-83.

(4) Abraham, M. H.; Ibrahim, A.; Zissimos, A. M. J. Chromatogr. A 2004, 1037, 29-47. 
TABLE 1. Descriptors for Anions and Neutral Species

\begin{tabular}{lllllll}
\hline \multicolumn{1}{c}{ compound } & $\mathbf{E}$ & $\mathbf{S}$ & $\mathbf{A}$ & $\mathbf{B}$ & $\mathbf{V}$ & $\mathbf{J}^{-}$ \\
\hline acetate & 0.415 & 2.19 & 0.00 & 2.93 & 0.4433 & 2.075 \\
benzoate & 0.880 & 3.64 & 0.00 & 2.88 & 0.9102 & 2.395 \\
$\begin{array}{l}\text { terephthalic acid, } \\
\quad \text { monoanion }\end{array}$ & 1.25 & 3.90 & 0.41 & 2.92 & 1.1255 & 2.323 \\
$\begin{array}{l}\text { terephthalic acid, } \\
\quad \text { dianion }\end{array}$ & 1.40 & 3.55 & 0.00 & 5.08 & 1.1040 & 3.356 \\
$\mathrm{~F}^{-}$ & -0.05 & 3.76 & 0.00 & 2.42 & 0.1050 & 2.385 \\
$\mathrm{Cl}^{-}$ & 0.10 & 3.52 & 0.00 & 2.32 & 0.2280 & 2.363 \\
Triethylamine $_{N, N \text {-dimethyl- }}$ & 1.01 & 0.15 & 0.00 & 0.79 & 1.0538 & 0 \\
$\quad 0.363$ & 1.38 & 0.00 & 0.80 & 0.7877 & 0 \\
$\quad$ acetamide & \\
succinamide & 0.850 & 1.98 & 0.97 & 1.13 & 0.9032 & 0 \\
$\begin{array}{l}\text { DMSO } \\
\text { tributylphosphine }\end{array}$ & -0.522 & 1.72 & 0.00 & 0.97 & 0.6126 & 0 \\
$\quad$ oxide & & 1.15 & 0.00 & 1.64 & 2.0627 & 0 \\
$\quad{ }^{a}$ Compounds as solutes. & & & & & \\
\hline
\end{tabular}

correlate and predict partitions in a very large number of systems. ${ }^{5-8}$

In order to obtain the solute descriptors for a given carboxylate anion, we first obtained $\log P$ values for as many water-solvent systems as possible. We fixed $\mathbf{E}$ for a carboxylate anion as $\mathbf{E}$ for the neutral acid plus 0.15 and fixed $\mathbf{V}$ for the anion as $\mathbf{V}$ for the neutral acid -0.0215 , so that three descriptors $\mathbf{S}, \mathbf{A}$, and $\mathbf{B}$ are unknown. In addition we found it necessary to include an additional descriptor $\mathbf{J}^{-}$to deal with ion-solvent interactions. Thus four descriptors, $\mathbf{S}, \mathbf{A}, \mathbf{B}$, and $\mathbf{J}^{-}$remained to be determined. If $\log P$ values in four solvents are available, then all four descriptors can be obtained. Even better, if $\log P$ values in more than four solvents are available, the four descriptors can be obtained by a trial-and-error method using "Solver" in Microsoft Excel, as explained in detail in ref 1 . For most carboxylate anions $\mathbf{A}=0$, and so only three descriptors were unknown. Some values of descriptors for carboxylate anions and neutral species are shown in Table 1 . The carboxylate anions are characterized by vary large values of $\mathbf{S}$ and $\mathbf{B}$; indeed they are the most powerful hydrogen bond bases we have encountered.

We would also expect phenoxide anions to be strong hydrogen bond bases, and it is the purpose of the present work to obtain descriptors for these anions, in the same way as we have done for the carboxylate anions.

\section{Results and Discussion}

There are a number of values of $\log P$ for phenoxide ions that have been obtained by the solubility method, as shown

(5) Abraham, M. H.; Smith, R. E.; Luchtefeld, R.; Boorem, A. J.; Luo, R.; Acree, W. E., Jr. J. Pharm. Sci. 2010, 99, 1500-1515.

(6) Sprunger, L. M.; Gibbs, J.; Proctor, A.; Acree, W. E., Jr.; Abraham, M. H.; Meng, Y.; Yao, C.; Anderson, J. L. Ind. Eng. Chem. 2009, 48, 4145-4154.

(7) Abraham, M. H.; Zissimos, A. M.; Huddleston, J. G.; Willauer, H. D.;

Rodgers, R. D.; Acree, W. E., Jr. Ind. Eng. Chem. Res. 2003, 42, 413-418.

(8) Zhao, Y. H.; Le, J.; Abraham, M. H.; Hersey, A.; Eddershaw, P. E.;

Luscombe, C. N.; Butina, D.; Beck, G.; Sherborne, B.; Cooper, I.; Platts,

J. A. J. Pharm. Sci. 2001, 90, 749-784.

(9) Marcus, Y. Pure Appl. Chem. 1983, 55, 977-1021.

(10) Marcus, Y. Chem. Rev. 2007, 107, 3880-3897.

(11) de Namor, A. F. D.; Traboulssi, R.; Salazar, F. F.; de Acosta, V. D.; de Vizcardo, Y. F.; Portugal, J. M. J. Chem. Soc., Faraday Trans. 1 1989, 85, 2705-2712.

(12) Rais, J. Collect. Czech. Chem. Commun. 1970, 36, 3253-3162.

(13) de Namor, A. F. D.; Hill, T.; Sigstad, E. J. Chem. Soc., Faraday Trans. 1 1983, 79, 2713-2722.

(14) Herrera, H. A.; Lopez, B. A.; Mishima, H. T. An. Asoc. Quim. Argent. 1986, 74, 207-214. in Table 2. ${ }^{9-14}$ In addition, Chopineaux-Courtois et al. ${ }^{15}$ have obtained partition coefficients to 1,2-dichloroethane (1,2-DCE) by an electrochemical method for a number of phenoxide anions, and a value is available ${ }^{16}$ for the $2,4-$ dinitrophenolate anion to nitrophenyloctyl ether (NPOE). Komorsky-Lovric ${ }^{17}$ et al. have determined $\log P$ values for a number of anions, including phenoxides, by an electrochemical method for transfer to nitrobenzene. All of these values for anions are based on the $\left(\mathrm{Ph}_{4} \mathrm{As}^{+}\right.$or $\left.\mathrm{Ph}_{4} \mathrm{P}^{+}\right)=\mathrm{Ph}_{4} \mathrm{~B}^{-}$ convention. Bouchard et al. ${ }^{18}$ have used an electrochemical method to obtain $\log P$ values for transfer of anions from water to wet octanol, but it should be noted that the values are not based on the $\left(\mathrm{Ph}_{4} \mathrm{As}^{+}\right.$or $\left.\mathrm{Ph}_{4} \mathrm{P}^{+}\right)=\mathrm{Ph}_{4} \mathrm{~B}^{-}$convention.

There are not enough $\log P$ values for any given phenoxide in Table 2 to attempt to calculate descriptors with the exception of those for the picrate anion. When we used these $\log P$ values we obtained descriptors for the picrate anion as follows: $\mathbf{E}=1.58, \mathbf{S}=0.84, \mathbf{A}=0.00, \mathbf{B}=0.89, \mathbf{V}=1.2762$, and $\mathbf{J}^{-}=-0.488$. These are fairly clearly in error, with values of $\mathbf{S}$ and $\mathbf{B}$ being far too small for an aromatic species with a full negative charge.

We therefore used eqs $1-3$ to obtain the required $\log P$ values for the picrate anion and for all of the other phenolate anions we studied. Values of $\mathrm{p} K_{\mathrm{a}}(\mathrm{aq})^{19,20}$ and of $\mathrm{p} K_{\mathrm{a}}(\mathrm{s})^{20-28}$ were from a variety of sources. $\log P(\mathrm{HA})$ and $\log P\left(\mathrm{H}^{+}\right)$in eq 3 are also required for the calculation. As before, we estimated $\log P(\mathrm{HA})$ for the neutral phenols from descriptors for phenols and the coefficients in eq 4 . We give the necessary descriptors in Table 3 together with values of $\mathrm{p} K_{\mathrm{a}}(\mathrm{w})$ that we used and the coefficients for the full eq 5 in Table 4. Note that for the neutral phenols $j=0$ in eq 5 , which then reverts to eq 4 . Values of $\log P\left(\mathrm{H}^{+}\right)$were as before. ${ }^{1}$

$$
\mathrm{SP}=c+e \mathbf{E}+s \mathbf{S}+a \mathbf{A}+b \mathbf{B}+v \mathbf{V}+j^{-} \mathbf{J}^{-}
$$

As we did for the carboxylate anions, we took $\mathbf{E}_{\mathbf{i}}$ for the phenoxides as $\mathbf{E}+0.15$, and $\mathbf{V}_{\mathbf{i}}$ as $\mathbf{V}-0.0215$. For all of the phenoxides we studied, $\mathbf{A}_{\mathbf{i}}=0$ and so the descriptors $\mathbf{S}_{\mathbf{i}}, \mathbf{B}_{\mathbf{i}}$, and $\mathbf{J}^{-}$remain determined. Even then, the number of phenoxides for which we had sufficient $\mathrm{p} K_{\mathrm{a}}(\mathrm{s})$ values was very limited. We therefore obtained the descriptors for these phenoxides and set up regression equations for $\mathbf{S}_{\mathbf{i}}, \mathbf{B}_{\mathbf{i}}$, and $\mathbf{J}^{-}$. Then for phenoxides for which we had only one or two

(15) Chopineaux-Courtois, V.; Reymond, F.; Bouchard, G.; Carrupt, P.-A.; Testa, B.; Girault, H. H. J. Am. Chem. Soc. 1999, 121, 1743-1747.

(16) Ulmeanu, S. M.; Jensen, H.; Bouchard, G.; Carrupt, P.-A.; Girault, H. H. Pharm. Res. 2003, 20, 1317-1322.

(17) Komorsky-Lovrić, S.; Riedl, K.; Gulaboski, R.; Mirčeski, V.; Scholz, F. Langmuir 2002, 18, 8000-8005.

(18) Bouchard, G.; Gallaned, A.; Carrupt, P.-A.; Gulabowski, R.; Mircĕski, V.; Scholz, F.; Girault, H. H. Phys. Chem. Chem. Phys. 2003, 5, 3748-3751.

(19) Tehan, B. G.; Lloyd, E. J.; Wong, M. G.; Pitt, W. R.; Montana, J. G.;

Manallack, D. T; Gancia, E. Ouant. Struct-Act. Relat. 2002, 21, 457-472.

(20) Jover, J.; Bosque, R.; Sales, J. QSAR Comb. Sci. 2007, 26, 385-397.

(21) Rived, F.; Rosés, M.; Bosch, E. Anal. Chim. Acta 1998, 374, 309-324.

(22) Bosch, E.; Rafols, C.; Rosés, M. Talanta 1989, 36, 1227-1231.

(23) Bosch, E.; Rosés, M. Anal. Chem. 1988, 60, 2008-2013.

(24) Kolthoff, I. M.; Chantooni, M. K., Jr. J. Am. Chem. Soc. 1976, 24, $7465-7470$.

(25) Bordwell, F. G.; Hughes, D. L. J. Org. Chem. 1982, 47, 3224-3232. (26) Lesniewski, B.; Przybyszewski, B.; Pawlak, Z. J. Chem. Soc., Faraday Trans. 1 1984, 80, 1769-1775.

(27) Chantooni, M. K., Jr.; Kolthoff, I. M. J. Phys. Chem. 1976, 80, $1308-1310$.

(28) Izutsu, K. Acid-Base Dissociation Constants in Dipolar Aprotic Solvents, IUPAC Chemical data series No. 35; Blackwell Scientific Publications: Oxford, 1990. 
TABLE 2. Values of $\log \boldsymbol{P}$ for Partition of Phenoxide Anions from Water to Solvents

\begin{tabular}{|c|c|c|c|c|c|c|c|c|c|c|}
\hline \multirow[b]{2}{*}{ solvent } & \multicolumn{10}{|c|}{ substituent } \\
\hline & 2,4,6-trinitro & 2,4-dinitro & 2,5-dinitro & 2,6-dinitro & 2-nitro & 3-nitro & 4-nitro & $\mathrm{H}$ & 2-Me & $2-\mathrm{Cl}$ \\
\hline methanol & $1.0,^{9} 0.6^{10}$ & & & & & & & & & \\
\hline ethanol & $-0.1,,^{9} 0.0^{10}$ & & & & & & & & & \\
\hline ethylene glycol & $1.2^{9,10}$ & & & & & & & & & \\
\hline PC & $1.0^{9}$ & & & & & & & & & \\
\hline formamide & $1.2,^{9} 1.7^{10}$ & & & & & & & & & \\
\hline DMF & $1.2^{9}$ & & & & & & & & & \\
\hline acetonitrile & $0.7^{9}$ & & & & & & & & & \\
\hline nitrobenzene & $0.8^{9,13,14}$ & $-1.3^{12}$ & & $-1.4^{12}$ & $-2.5^{17}$ & & & $-3.6^{17}$ & $-3.9^{17}$ & $-2.9^{17}$ \\
\hline dichloromethane & $-0.7^{11}$ & & & & & & & & & \\
\hline $1,2-\mathrm{DCE}^{15}$ & & -1.7 & -2.3 & & -2.0 & -2.4 & -2.5 & -2.3 & & \\
\hline NPOE & & $-2.2^{16}$ & & & & & & & & \\
\hline octanol (wet) ${ }^{18}$ & & 0.8 & 0.8 & & 0.7 & 0.7 & 0.8 & 0.7 & & \\
\hline
\end{tabular}

$\mathrm{p} K_{\mathrm{a}}(\mathrm{s})$ values we used a combination of predicted values of descriptors from the regression equations and the $\log P$ values from eqs $1-3$ to obtain a set of descriptors that were compatible with both. From time to time the regression equations were recalculated until we had a self-consistent set of regression equations and descriptors. We then used the final regression equations to predict descriptors for a number of phenoxides with rather simple substituents. For independent variables in the regression equations we used, as before, the descriptors for the neutral phenols, but in addition we included $\mathrm{p} K_{\mathrm{a}}(\mathrm{aq})$ as an independent variable. The final regression equations are eqs $6-10$. We give the subscript "i" to distinguish descriptors for the anions from descriptors for the corresponding neutral species. Otherwise we use the symbols without the subscript for both anions and neutral species. Equation 7, 8 , and 10 are simply empirical equations that use readily available parameters as the independent variables. It is interesting that $\mathrm{p} K_{\mathrm{a}}(\mathrm{w})$ is a useful descriptor for prediction of descriptors for phenolate anions but not for carboxylate anions or protonated amine cations. ${ }^{1}$ We note that in similar work on pyridinium cations we have found that $\mathrm{p} K_{\mathrm{a}}(\mathrm{w})$ is also a useful independent variable. Both for the phenolate anions and pyridinium cations, the substrates are all substituted aromatics, and so $\mathrm{p} K_{\mathrm{a}}(\mathrm{w})$ acts a Hammett substituent constant.

$$
\mathbf{E}_{\mathbf{i}}=0.15+1.00 \mathbf{E}
$$

$\mathbf{S}_{\mathbf{i}}=4.692+4.639 \mathbf{E}-2.900 \mathbf{S}+5.326 \mathbf{A}+5.218 \mathbf{B}-0.776 \mathrm{p} K_{\mathrm{a}}(\mathrm{w})$

$\mathbf{B}_{\mathbf{i}}=1.700+1.103 \mathbf{E}-0.732 \mathbf{S}+0.728 \mathbf{A}+0.564 \mathbf{B}-0.0255 \mathrm{p} K_{\mathrm{a}}(\mathrm{w})$

$$
\mathbf{V}_{\mathbf{i}}=-0.0215+1.00 \mathbf{V}
$$

$$
\mathbf{J}^{-}=2.165+2.579 \mathbf{E}-1.504 \mathbf{S}+1.708 \mathbf{A}+0.045 \mathbf{B}-0.217 \mathrm{p} K_{\mathrm{a}}(\mathrm{w})
$$

Equations 6-10 could be used to predict descriptors for other phenoxides with reasonably simple substituents. We have not been able to obtain descriptors for phenoxides that contain hydrogen bond acid groups such as $\mathrm{OH}$, and so the descriptor $\mathbf{A}=0$ for all the phenoxide anions we have studied. The descriptors for the phenoxides are in Table 5, together with the number of $\log P$ values that we used and the standard deviation, SD, between the observed and predicted $\log P$.
Where no number is given, the descriptors have been predicted through eqs $6-10$. The $\log P$ values that were obtained through eqs $1-3$ are in Table S1 in Supporting Information, together with the references ${ }^{20-28}$ for the $\mathrm{p} K_{\mathrm{a}}(\mathrm{s})$ values.

The main features of the descriptors are the very large values of the dipolarity/polarizability descriptor, $\mathbf{S}$, and the hydrogen bond basicity descriptor $\mathbf{B}$. These large values are not surprising, given that all of the phenoxides have a full negative charge, although they are not quite as large as for the benzoate anions; see Table 1. Polar substituents such as $\mathrm{Cl}, \mathrm{Br}, \mathrm{I}, \mathrm{CHO}, \mathrm{CN}$, and $\mathrm{NO}_{2}$ increase $\mathbf{S}$ considerably, but have less effect on $\mathbf{B}$. We suggest that eqs $6-10$ can be used to estimate descriptors for other substituted or polysubstituted phenoxide anions with substituents listed in Table 5.

We noted above that descriptors calculated for the picrate anion from solubility derived $\log P$ values were substantially different to those calculated through eqs $1-3$. In Table 6 we compare the solubility derived $\log P$ values with those for the picrate anion that we calculate from the descriptors in Table 5 and the solvent coefficients in Table 4.

There are considerable differences between the two sets of data. A possible difficulty with the solubility method is that it relies on there being no solvate formation with the picrate salt in the organic solvents.

On the other hand, there is reasonable agreement between $\log P$ values for nitro substituted phenoxides calculated from our descriptors, and $\log P$ values by electrochemical methods. In Table 7 we compare electrochemical values for transfer to the somewhat dipolar aprotic solvent, nitrobenzene (see also Table 2), with calculated $\log P$ values to acetonitrile, also a dipolar aprotic solvent. In both cases, there is a marked increase in $\log P$ with the number of nitro substituents. However, for the hydroxylic solvents wet octanol (see also Table 2) and methanol, there is very little change in $\log P$ with increase in the number of substituents.

The descriptors for the phenoxide anions can clearly be used to help characterize other water-solvent systems in terms of eq 5, but we were interested to see if the descriptors could be of wider use. One quite different system is the Finkelstein reaction of anions with haloalkanes. Data are available for the kinetics of reaction of anions with iodomethane in methanol, ${ }^{29-31} \mathrm{~N}, \mathrm{~N}$-dimethylformamide

(29) Cook, D.; Evans, I. P.; Ko, E. C. F.; Parker, A. J. J. Chem. Soc. B 1966, 404-409.

(30) Pearson, R. G.; Sobel, H.; Songstad, J. J. Am. Chem. Soc. 1968, 90, $319-326$.

(31) Parker, A. J. J. Chem. Soc. 1961, 1328-1337. 
TABLE 3. Descriptors for Phenols

\begin{tabular}{|c|c|c|c|c|c|c|}
\hline substituent & $\mathbf{E}$ & $S$ & $\mathbf{A}$ & B & $\mathbf{V}$ & $\overline{\mathrm{p} K_{\mathrm{a}}(\mathrm{w})}$ \\
\hline$\overline{\mathrm{H}}$ & 0.805 & 0.89 & 0.60 & 0.30 & 0.7751 & 9.99 \\
\hline 2-methyl & 0.840 & 0.86 & 0.52 & 0.30 & 0.9160 & 10.31 \\
\hline 3-methyl & 0.822 & 0.88 & 0.57 & 0.34 & 0.9160 & 10.10 \\
\hline 4-methyl & 0.820 & 0.87 & 0.57 & 0.31 & 0.9160 & 10.28 \\
\hline 2,3-dimethyl & 0.850 & 0.82 & 0.51 & 0.37 & 1.0569 & 10.54 \\
\hline 2,4-dimethyl & 0.843 & 0.79 & 0.52 & 0.40 & 1.0569 & 10.60 \\
\hline 2,5-dimethyl & 0.840 & 0.83 & 0.50 & 0.38 & 1.0569 & 10.41 \\
\hline 2,6-dimethyl & 0.840 & 0.79 & 0.39 & 0.38 & 1.0569 & 10.59 \\
\hline 3,4-dimethyl & 0.830 & 0.90 & 0.55 & 0.38 & 1.0569 & 10.36 \\
\hline 3,5-dimethyl & 0.830 & 0.86 & 0.55 & 0.37 & 1.0569 & 10.20 \\
\hline 2-ethyl & 0.831 & 0.84 & 0.52 & 0.37 & 1.0569 & 10.42 \\
\hline 3-ethyl & 0.810 & 0.91 & 0.55 & 0.37 & 1.0569 & 9.90 \\
\hline 4-ethyl & 0.800 & 0.90 & 0.55 & 0.36 & 1.0569 & 10.00 \\
\hline 4-t-butyl & 0.810 & 0.91 & 0.56 & 0.40 & 1.3387 & 10.31 \\
\hline 2-fluoro & 0.660 & 0.69 & 0.61 & 0.26 & 0.7928 & 8.73 \\
\hline 3-fluoro & 0.667 & 0.98 & 0.68 & 0.17 & 0.7928 & 9.21 \\
\hline 4-fluoro & 0.670 & 0.97 & 0.63 & 0.23 & 0.7928 & 9.97 \\
\hline $\begin{array}{l}\text { 3-trifluoro- } \\
\text { methyl }\end{array}$ & 0.425 & 0.51 & 0.85 & 0.15 & 0.9691 & 8.95 \\
\hline $\begin{array}{l}\text { 4-trifluoro- } \\
\text { methyl }\end{array}$ & 0.420 & 0.57 & 0.84 & 0.17 & 0.9691 & 8.68 \\
\hline 2-chloro & 0.853 & 0.88 & 0.32 & 0.31 & 0.8975 & 8.48 \\
\hline 3-chloro & 0.909 & 1.06 & 0.69 & 0.15 & 0.8975 & 9.02 \\
\hline 4-chloro & 0.915 & 1.08 & 0.67 & 0.20 & 0.8975 & 9.38 \\
\hline 2,4-dichloro & 0.960 & 0.82 & 0.54 & 0.17 & 1.0199 & 7.85 \\
\hline 2,5-dichloro & 0.960 & 0.84 & 0.52 & 0.18 & 1.0199 & 7.51 \\
\hline 2,6-dichloro & 0.900 & 0.86 & 0.36 & 0.24 & 1.0199 & 6.79 \\
\hline 3,4-dichloro & 1.020 & 1.24 & 0.93 & 0.00 & 1.0199 & 8.63 \\
\hline 3,5-dichloro & 1.020 & 1.02 & 0.92 & 0.00 & 1.0199 & 8.18 \\
\hline 2-bromo & 1.037 & 0.90 & 0.35 & 0.31 & 0.9501 & 8.41 \\
\hline 3-bromo & 1.060 & 1.13 & 0.70 & 0.16 & 0.9501 & 9.01 \\
\hline 4-bromo & 1.080 & 1.17 & 0.67 & 0.20 & 0.9501 & 9.36 \\
\hline 2-iodo & 1.360 & 1.00 & 0.40 & 0.35 & 1.0333 & 8.46 \\
\hline 3-iodo & 1.370 & 1.20 & 0.70 & 0.18 & 1.0333 & 8.88 \\
\hline 4-iodo & 1.380 & 1.22 & 0.68 & 0.20 & 1.0333 & 9.30 \\
\hline $\begin{array}{l}\text { 2-chloro- } \\
\text { 4-bromo }\end{array}$ & 1.150 & 0.91 & 0.50 & 0.22 & 1.0725 & 7.64 \\
\hline $\begin{array}{l}\text { 2-chloro- } \\
\text { 4-phenyl }\end{array}$ & 1.650 & 1.31 & 0.32 & 0.39 & 1.5053 & 8.07 \\
\hline 2-nitro & 1.015 & 1.05 & 0.05 & 0.37 & 0.9493 & 7.23 \\
\hline 3-nitro & 1.050 & 1.57 & 0.79 & 0.23 & 0.9493 & 8.36 \\
\hline 4-nitro & 1.070 & 1.72 & 0.82 & 0.26 & 0.9493 & 7.18 \\
\hline 2,4-dinitro & 1.200 & 1.49 & 0.09 & 0.56 & 1.1235 & 4.10 \\
\hline 2,5 -din & 1.260 & 1.45 & 0.11 & 0.54 & 1.1235 & 5.22 \\
\hline 2,6-dinitro & 1.220 & 2.04 & 0.17 & 0.48 & 1.1235 & 3.74 \\
\hline $3,4-\mathrm{d}$ & .320 & 2.25 & 1.14 & 0.16 & 1.1 & 5.42 \\
\hline 3,5-dinitro & 1.320 & 2.18 & 1.05 & 0.16 & 1.1235 & 6.66 \\
\hline 2,4,6-trinitro & 1.430 & 2.66 & 0.46 & 0.42 & 1.2977 & 0.43 \\
\hline $\begin{array}{l}\text { 2,6-dibromo- } \\
\text { 4-nitro }\end{array}$ & 1.560 & 1.76 & 0.71 & 0.15 & 1.2993 & 3.38 \\
\hline $\begin{array}{l}\text { 3-trifluoro- } \\
\text { methyl-4-nitro }\end{array}$ & 0.690 & 1.44 & 1.25 & 0.13 & 1.1433 & 6.41 \\
\hline $\begin{array}{l}\text { 2,6-di-tert-- } \\
\text { butyl-4-nitro }\end{array}$ & 1.050 & 1.74 & 0.45 & 0.51 & 2.0765 & 6.62 \\
\hline $\begin{array}{l}\text { 2-methyl-4, } \\
\text { 6-dinitro }\end{array}$ & 1.200 & 1.59 & 0.04 & 0.52 & 1.2644 & 4.35 \\
\hline 2-cyano & .920 & 1.33 & 0.78 & 0.34 & 0.9298 & 7.13 \\
\hline 3-cyano & 0.930 & 1.55 & 0.84 & 0.25 & 0.9298 & 8.61 \\
\hline 4-cyano & .940 & 1.63 & 0.80 & 0.29 & 0.9298 & 7.80 \\
\hline $3-\mathrm{CHO}$ & 0.990 & 1.38 & 0.73 & 0.40 & 0.9317 & 8.61 \\
\hline $4-\mathrm{CHO}$ & .010 & 1.39 & 0.80 & 0.44 & 0.9317 & 7.51 \\
\hline 1-naphthol & 1.520 & 1.10 & 0.66 & 0.34 & 1.1441 & 9.40 \\
\hline 2-naphthol & 1.520 & 1.08 & 0.61 & 0.40 & 1.1441 & 9.51 \\
\hline 3-methoxy & 0.879 & 1.17 & 0.59 & 0.39 & 0.9747 & 9.65 \\
\hline 4-methoxy & 0.900 & 1.17 & 0.57 & 0.48 & 0.9747 & 10.27 \\
\hline thyms & 0.822 & 0.84 & 0.44 & 0.43 & 1.3387 & 10.49 \\
\hline carvacrol & 0.824 & 0.81 & 0.56 & 0.43 & 1.3387 & 10.35 \\
\hline eugenol & 0.946 & 0.98 & 0.26 & 0.65 & 1.3544 & 10.19 \\
\hline thio & 000 & 0.80 & 0.12 & 0.17 & 0.8799 & 6.61 \\
\hline $\begin{array}{l}\text { 4-methylthio- } \\
\text { phenol }\end{array}$ & 0.950 & 0.80 & 0.12 & 0.17 & 1.0208 & 6.82 \\
\hline
\end{tabular}

TABLE 4. Coefficients in the Solvent Equations (eqs 4 and 5) ${ }^{a}$

\begin{tabular}{lccrrrrr}
\hline \multicolumn{1}{c}{ solvent } & $c$ & $e$ & \multicolumn{1}{c}{$s$} & \multicolumn{1}{c}{$a$} & \multicolumn{1}{c}{$b$} & $v$ & $j^{-}$ \\
\hline propanone & 0.313 & 0.312 & -0.121 & -0.608 & -4.753 & 3.942 & 0.078 \\
acetonitrile & 0.413 & 0.077 & 0.326 & -1.566 & -4.391 & 3.364 & 0.101 \\
$\begin{array}{c}N \text {-methylpyrro- } \\
\text { lidinone }\end{array}$ & 0.147 & 0.532 & 0.275 & 0.840 & -4.794 & 3.674 & 0.105 \\
$\begin{array}{c}\text { dimethyl- } \\
\text { formamide }\end{array}$ & -0.305 & -0.058 & 0.343 & 0.357 & -4.865 & 4.486 & 0.415 \\
$\begin{array}{l}\text { dimethyl- } \\
\quad \text { sulfoxide }\end{array}$ & -0.194 & 0.327 & 0.791 & 1.260 & -4.540 & 3.361 & 0.132 \\
$\begin{array}{l}\text { methanol } \\
\text { ethanol }\end{array}$ & 0.276 & 0.334 & -0.714 & 0.243 & -3.320 & 3.549 & 3.027 \\
propan-2-ol & 0.222 & 0.471 & -1.035 & 0.326 & -3.596 & 3.857 & 3.085 \\
tert-butanol & 0.099 & 0.344 & -1.049 & 0.406 & -3.827 & 4.033 & 2.889 \\
& 0.211 & 0.171 & -0.947 & 0.331 & -4.085 & 4.109 & 2.953
\end{tabular}

${ }^{a}$ The coefficient $j^{-}$is zero for neutral species, thus leading to eq 4 .

(DMF), ${ }^{29,31,32}$ and water ${ }^{33,34}$ at $298 \mathrm{~K}$, and in Table 8 we give rate constants as $\log k$ with $k$ in $1 \mathrm{~mol}^{-1} \mathrm{~s}^{-1}$. There is not a great deal of data, but we have constructed eqs 11-13 for the correlation of the $\log k$ values in the three solvents. The given statistics are $N$, the number of data points; $\mathrm{SD}$, the regression standard deviation; $R$, the correlation coefficient; and $F$, the $F$-statistic. The leave-one-out statistics are $Q^{2}$ and PSD, the "predictive" standard deviation, as defined previously. ${ }^{35}$

$$
\begin{gathered}
\log k(\mathrm{MeOH})=3.58-1.58 \mathbf{S}-4.92 \mathbf{B}+3.09 \mathbf{V}+3.08 \mathbf{J}^{-} \\
N=15, \mathrm{SD}=0.66, R^{2}=0.934, F=35.4 \\
Q^{2}=0.724, \mathrm{PSD}=1.36 \\
\log k(\mathrm{DMF})=3.70-1.94 \mathbf{S}-3.16 \mathbf{B}+4.83 \mathbf{J}^{-} \\
N=13, \mathrm{SD}=0.61, R^{2}=0.921, F=35.1 \\
Q^{2}=0.821, \mathrm{PSD}=0.92 \\
\log k(\text { water })=2.88-0.88 \mathbf{S}-2.44 \mathbf{B} \\
N=10, \mathrm{SD}=0.44, R^{2}=0.946, F=61.4 \\
Q^{2}=0.861, \mathrm{PSD}=0.71
\end{gathered}
$$

The statistics for eqs 11-13 are reasonably satisfactory, although the large values of PSD suggests that none of them could be used to predict further values of $\log k$ with any accuracy. In Figures 1-3 we plot calculated versus observed values of $\log k$ using eqs $11-13$. The figures all show that the data points for the phenoxide anions lie on the same lines as the permanent ions and carboxylate anions, so that the descriptors for the phenoxide anions can certainly be used to analyze quite different systems to the water-solvent systems. Equations 11 and 12 could not have been constructed without data for the phenoxide anions, an indication of how useful the descriptors for the phenoxide anions could be. If there are enough data on, say, benzoate anions or

(32) Alexander, R.; Ko, E. C. F.; Parker, A. J.; Broxton, T. J. J. Am. Chem. Soc. 1968, 90, 5049-5069.

(33) Koivurinta, J.; Kyllönen, A.; Leinonen, L.; Valaste, K.; Koskikallio, J. Finn. Chem. Lett. 1974, 239-243.

(34) Bathgate, R. H.; Moelwyn-Hughes, E. A. J. Chem. Soc. 1959, 26422648.

(35) Abraham, M. H.; Acree, W. E., Jr.; Leo, A. J.; Hoekman, D. New J. Chem. 2009, 33, 568-573. 
TABLE 5. Descriptors for Phenoxide Anions

\begin{tabular}{|c|c|c|c|c|c|c|c|}
\hline substituent & $\mathbf{E}_{\mathbf{i}}$ & $S_{i}$ & $\mathbf{B}_{\mathbf{i}}$ & vi & $\mathbf{J}^{-}$ & $N^{a}$ & $\overline{\mathrm{SD}^{b}}$ \\
\hline$\overline{\mathrm{H}}$ & 0.955 & 2.80 & 2.12 & 0.7536 & 1.6760 & 5 & 0.3 \\
\hline 2-methyl & 0.990 & 2.75 & 2.18 & 0.8945 & 1.6500 & 1 & \\
\hline 3-methyl & 0.972 & 2.80 & 2.10 & 0.8945 & 1.6100 & 1 & \\
\hline 4-methyl & 0.970 & 2.75 & 2.10 & 0.8945 & 1.6560 & 1 & \\
\hline 2,3-dimethyl & 1.000 & 2.80 & 2.27 & 1.0354 & 1.7000 & 1 & \\
\hline 2,4-dimethyl & 0.993 & 2.80 & 2.26 & 1.0354 & 1.7000 & 1 & \\
\hline 2,5-dimethyl & 0.990 & 2.80 & 2.32 & 1.0354 & 1.7000 & 1 & \\
\hline 2,6-dimethyl & 0.990 & 2.80 & 2.32 & 1.0354 & 1.7000 & 1 & \\
\hline 3,4-dimethyl & 0.980 & 2.71 & 2.23 & 1.0354 & 1.7000 & 1 & \\
\hline 3,5-dimethyl & 0.980 & 2.71 & 2.24 & 1.0354 & 1.7000 & 1 & \\
\hline 2-ethyl & 0.981 & 2.73 & 2.32 & 1.0354 & 1.6885 & 0 & \\
\hline 3-ethyl & 0.960 & 2.99 & 2.28 & 1.0354 & 1.6931 & 0 & \\
\hline 4-ethyl & 0.950 & 2.84 & 2.27 & 1.0354 & 1.6602 & 0 & \\
\hline 4-t-butyl & 0.960 & 3.22 & 2.30 & 1.3172 & 1.9000 & 1 & \\
\hline 2-fluoro & 0.810 & 3.90 & 2.27 & 0.7713 & 2.2300 & 1 & \\
\hline 3-fluoro & 0.817 & 2.31 & 2.07 & 0.7713 & 1.5818 & 0 & \\
\hline 4-fluoro & 0.820 & 1.81 & 2.06 & 0.7713 & 1.3570 & 0 & \\
\hline 3-trifluoro & 0.575 & 3.55 & 2.35 & 0.9476 & 1.9800 & 2 & \\
\hline 4-trifluoro & 0.570 & 3.61 & 2.23 & 0.9476 & 1.9497 & 0 & \\
\hline 2-chloro & 1.003 & 2.98 & 2.20 & 0.8760 & 1.7600 & 2 & 0.12 \\
\hline 3-chloro & 1.059 & 3.24 & 2.27 & 0.8760 & 2.1500 & 2 & 0.03 \\
\hline 4-chloro & 1.065 & 2.95 & 2.38 & 0.8760 & 2.0200 & 4 & 0.35 \\
\hline 2,4-dichloro & 1.110 & 4.45 & 2.49 & 0.9984 & 2.7500 & 2 & 0.3 \\
\hline 2,5-dichloro & 1.110 & 4.45 & 2.42 & 0.9984 & 2.6360 & 1 & \\
\hline 2,6-dichloro & 1.050 & 4.12 & 2.38 & 0.9984 & 2.3500 & 3 & 0.4 \\
\hline hloro & 1.170 & 4.02 & 2.37 & 0.9984 & 2.6565 & 1 & \\
\hline 3,5-dichloro & 1.170 & 5.30 & 2.44 & 0.9984 & 3.0300 & 3 & 0.44 \\
\hline 2-bromo & 1.187 & 3.78 & 2.36 & 0.9286 & 2.2900 & 2 & \\
\hline 3-bromo & 1.210 & 4.00 & 2.44 & 0.9286 & 2.4300 & 1 & \\
\hline 4-bromo & 1.230 & 3.50 & 2.46 & 0.9286 & 2.3000 & 4 & 0.2 \\
\hline 2-iodo & 10 & 5.49 & 2.74 & 1.0118 & 3.0316 & 0 & \\
\hline 3-iodo & 20 & 5.34 & 2.72 & 1.0 & 02 & 0 & \\
\hline 4-iodo & 30 & 5.00 & 2.70 & 1.0 & 3.0415 & 0 & \\
\hline 2-chlorc & 1.300 & 5.27 & 2.60 & 1.0510 & 2.9682 & 0 & \\
\hline 2-chloro-4 & 1.800 & 6.02 & 2.81 & 1.4838 & 3.2630 & 0 & \\
\hline 2-nitro & 1.165 & 2.95 & 2.20 & 0.9278 & 1.7200 & 5 & 0.2 \\
\hline 3-nitro & 1.200 & 3.80 & 2.25 & 0.9278 & 2.0600 & 6 & 0.52 \\
\hline 4-nitro & 1.220 & 4.85 & 2.09 & 0.9278 & 2.2000 & 7 & 0.14 \\
\hline & 1.350 & 6.64 & 2.25 & 1.1020 & 2.4760 & 6 & \\
\hline 2,5-dinitro & 1.410 & 5.03 & 2.24 & 1.1020 & 2.1040 & 4 & 0. \\
\hline 2,6-dinitro & 1.370 & 5.00 & 1.91 & 1.1020 & 1.6190 & 5 & \\
\hline 3,4-dinitro & 1.470 & 7.43 & 2.35 & 1.1020 & 2.9900 & 1 & \\
\hline 3,5-dinitro & 1.470 & 6.05 & 2.12 & 1.1020 & 2.9600 & 4 & 0.36 \\
\hline 2,4,6-trinitro & 1.580 & 7.75 & 1.76 & 1.2762 & 2.6300 & 4 & 0.2 \\
\hline 2,6-dibromo- & 1.710 & 8.70 & 2.65 & 1.2778 & 3.9500 & 1 & \\
\hline 3-trifluoromethyl-4-nitro & 0.840 & 6.08 & 2.23 & 1.1218 & 2.5286 & 0 & \\
\hline $\begin{array}{l}\text { 2,6-di-tert- } \\
\text { butyl-4-nitro }\end{array}$ & 1.200 & 4.45 & 2.04 & 2.0550 & 1.6100 & 2 & \\
\hline 2-methyl-4,6-dinitro & 350 & 5.50 & 2.02 & 1.2 & 1.9400 & 2 & 0. \\
\hline 2-cyano & 1.070 & 5.50 & 2.32 & 0.9083 & 2.3377 & 1 & \\
\hline 3-cyano & 1.080 & 3.50 & 2.30 & 0.9083 & 1.7000 & 1 & \\
\hline 4-cyar & 1.090 & 4.40 & 2.31 & 0.9083 & 1.7800 & 1 & \\
\hline $3-\mathrm{CHO}$ & 1.140 & 4.58 & 2.32 & 0.9102 & 2.0392 & 0 & \\
\hline 4-CHO & 1.160 & 6.08 & 2.44 & 0.9102 & 2.4358 & 0 & \\
\hline 3-acetyl & 1.130 & 4.90 & 2.39 & 1.0511 & 1.922 & 0 & \\
\hline 4-acetyl & 1.160 & 5.70 & 2.38 & 1.0511 & 2.140 & 0 & \\
\hline 1-naphthol & 1.670 & 6.55 & 3.00 & 1.1226 & 3.5335 & 0 & \\
\hline 2-naphthol & 1.670 & 6.57 & 3.01 & 1.1226 & 3.4570 & 0 & \\
\hline 3-methoxy & 1.029 & 3.07 & 2.22 & 0.9532 & 1.6035 & 0 & \\
\hline 4-methoxy & 1.050 & 3.05 & 2.26 & 0.9532 & 1.4930 & 0 & \\
\hline & 0.972 & 2.52 & 2.29 & 1.3172 & 1.5161 & 0 & \\
\hline carvacrol & 0.974 & 3.36 & 2.40 & 1.3172 & 1.8017 & 0 & \\
\hline eugenol & 1.096 & 3.11 & 2.32 & 1.3329 & 1.3929 & 0 & \\
\hline & & 3.03 & 1.85 & 0.8 & 2.3160 & 2 & 0.0 \\
\hline 4-methylthiophenol & 1.100 & 3.03 & 1.85 & 0.9993 & 2.2720 & 1 & \\
\hline
\end{tabular}

${ }^{a}$ The number of $\log P$ values used to calculate the descriptors. ${ }^{b}$ The standard deviation between observed and fitted $\log P$ values.
TABLE 6. Comparison of $\log P$ Values for the Picrate Anion by the Solubility Method, Table 2, and by Equations 1-3

\begin{tabular}{lcc}
\hline solvent & Table 2 & eqs $1-3$ \\
\hline methanol & 0.8 & 1.9 \\
ethanol & -0.1 & -0.4 \\
DMF & 1.2 & 0.5 \\
acetonitrile & 0.7 & -0.1 \\
\hline
\end{tabular}

TABLE 7. Comparison of $\log P$ Values for Nitro-Substituted Phenoxides by Electrochemical Methods and by Equations 1-3

\begin{tabular}{|c|c|c|c|c|c|c|c|c|}
\hline \multirow[b]{2}{*}{ solvent } & \multicolumn{8}{|c|}{ phenoxide } \\
\hline & $\begin{array}{c}2,4,6- \\
\text { trinitro }\end{array}$ & $\begin{array}{c}2,4- \\
\text { dinitro }\end{array}$ & $\begin{array}{c}2,5- \\
\text { dinitro }\end{array}$ & $\begin{array}{c}2,6- \\
\text { dinitro }\end{array}$ & $\begin{array}{c}2- \\
\text { nitro }\end{array}$ & $\begin{array}{c}\text { 3- } \\
\text { nitro }\end{array}$ & $\begin{array}{c}\text { 4- } \\
\text { nitro }\end{array}$ & $\mathrm{H}$ \\
\hline nitrobenzene $^{a}$ & 0.8 & -1.3 & & -1.4 & -2.5 & & & -3 \\
\hline $\begin{array}{c}\text { acetonitrile, } \\
\text { this work }\end{array}$ & -0.1 & -3.2 & -3.8 & -2.4 & -4.9 & -3.8 & -3.8 & -5.2 \\
\hline $\begin{array}{l}\text { octanol } \\
\text { (wet) }^{a}\end{array}$ & & 0.8 & 0.8 & & 0.7 & 0.7 & 0.8 & 0.7 \\
\hline $\begin{array}{l}\text { methanol, } \\
\text { this work }\end{array}$ & 1.9 & -0.1 & 0.0 & -0.4 & -0.2 & 0.0 & 0.2 & -0.6 \\
\hline
\end{tabular}

${ }^{a}$ Electrochemical method, see Table 2.

TABLE 8. Rate Constants, as $\log k$, in $1 \mathrm{~mol}^{-1} \mathrm{~s}^{-1}$ at $298 \mathrm{~K}$, for the Reaction of Anions with Iodomethane in Methanol, DMF, and Water Solvents

\begin{tabular}{lccc}
\hline & \multicolumn{3}{c}{$\log k$} \\
\cline { 2 - 4 } \multicolumn{1}{c}{ anion } & methanol & DMF & water \\
\hline fluoride & -7.30 & & -7.17 \\
chloride & -5.52 & 0.38 & -5.48 \\
bromide & -4.10 & 0.06 & -4.38 \\
iodide & -2.47 & & -3.24 \\
azide & -4.11 & 0.50 & -4.12 \\
thiocyanate & -3.24 & -1.10 & -3.45 \\
cyanide & -3.19 & 2.50 & -3.24 \\
nitrate & & & -8.08 \\
acetate & -5.57 & -0.07 & -6.07 \\
chloroacetate & -5.94 & -0.56 & \\
dichloroacetate & & -1.79 & \\
benzoate & -5.70 & -0.60 & \\
phenoxide & -4.14 & 0.74 & -4.43 \\
4-nitrophenoxide & -5.48 & -1.87 & \\
2,4-dinitrophenoxide & -7.05 & -3.67 & \\
picrate & -8.86 & -4.56 & \\
thiophenoxide & 0.03 & & \\
\hline
\end{tabular}

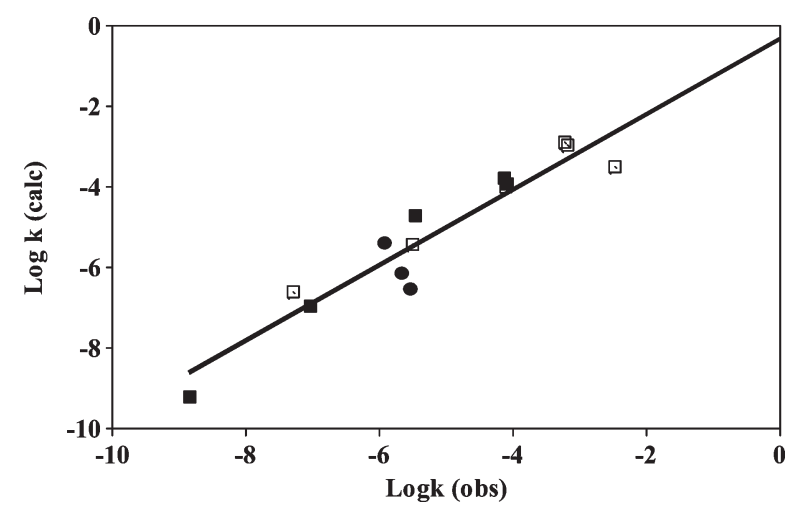

FIGURE 1. Plot of $\log k$ for reaction of iodomethane with anions in methanol solvent, calculated by eq 11, against the observed values of $\log k: \square$ permanent anions; $\square$ phenoxide anions; carboxylate anions. 


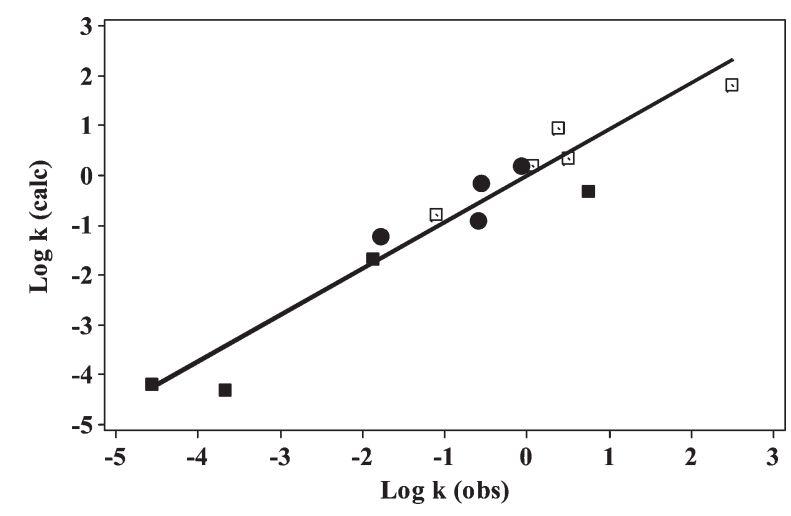

FIGURE 2. Plot of $\log k$ for reaction of iodomethane with anions in DMF solvent, calculated by eq 12 , against the observed values of log $k: \square$ permanent anions; phenoxide anions; carboxylate anions.

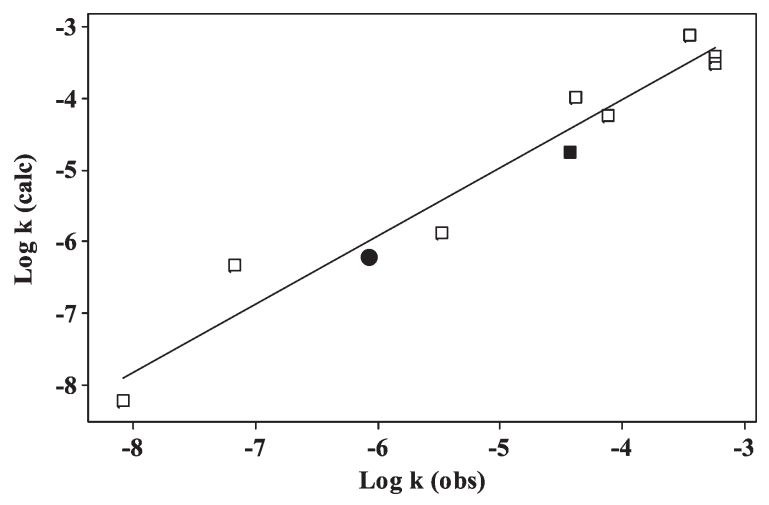

FIGURE 3. Plot of $\log k$ for reaction of iodomethane with anions in water solvent, calculated by eq 13 , against the observed values of log $k$ : $\square$ permanent anions; phenoxide anions; carboxylate anions.

phenoxide anions separately, then it might be possible to apply the Hammett equation to each data set. However, it is not possible to do so for a system that includes both benzoate anions and phenoxide anions, let alone nonaromatic carboxylate anions. The present results show that it is now possible to set up equations that include permanent anions, carboxylate anions, and phenoxide anions for kinetic processes as well as equilibrium processes. This greatly enhances the utility of the obtained phenoxide anion descriptors and the predictive equations, eqs $6-10$.

Swain and $\operatorname{Scott}^{36}$ set out a scale of nucleophilic constants, $n$, derived from $\log k$ values for reaction of anions and neutral molecules with haloalkanes in solvents that were either water or were largely aqueous. They interpreted the $n$ values in terms of transition state effects only, but Alexander

(36) Swain, C. G.; Scott, C. B. J. Am. Chem. Soc. 1953, 75, 141-147. et al. ${ }^{32}$ showed that solvation of the anions must be an important effect. This is also the conclusion we derive from inspection of eqs $11-13$. The $b$-coefficient in these equations is always negative, suggesting that the availability of lone pairs of electrons on the anion actually leads to a decrease in reactivity. The anions are more solvated by the solvent than are the transition states. Interestingly, neutral species such as aliphatic amines that would be regarded as less "nucleophilic" than negatively charged anions react faster with iodomethane than do the anions. For example $\log k$ for the reaction of dimethylamine with iodomethane in water at $298 \mathrm{~K}$ is $-2.04,{ }^{37}$ larger than $\log k$ for any of the anions in Table 8. Relative to the transition state, dimethylamine is less solvated than are anions.

We have shown on many occasions that regression equations for partition coefficients of solutes, as $\log P$, can be interpreted in terms of eq 4 to factor out the various effects that lead to differences in $\log P$ among solutes. We have now considerably extended the scope of such analyses, not only to charged species but to rate constants as well as to equilibrium constants.

\section{Conclusions}

We have been able to obtain a set of descriptors for phenoxide anions, using the variation of $\mathrm{p} K_{\mathrm{a}}$ of phenols with solvent. These descriptors are on the same scales as descriptors we have previously obtained for neutral species and for other anions, and allow equations to be constructed for partition coefficients from water to organic solvents, as log $P$ values, that include permanent anions, carboxylate anions, phenoxide anions, and neutral species in the same equation. Other equations have been constructed that allow the estimation of descriptors for further phenoxides, with a quite large range of substituents. The phenoxides are characterized by large values of the descriptors $\mathbf{S}$ and $\mathbf{B}$, in a similar fashion to the carboxylate anions. Through an analysis of some Finkelstein reactions, we show that the obtained descriptors for phenoxides will have utility in the analysis of rate constants as well as of equilibrium (partition) coefficients. In the case of the picrate anion, $\log P$ values from water to various solvents are not compatible with $\log P$ values calculated from our descriptors.

Supporting Information Available: Details of data used for calculations of descriptors for the phenoxide anions. This material is available free of charge via the Internet at http://pubs.acs.org.

(37) Okamoto, K.; Fukui, S.; Shingu, H. Bull. Chem. Soc. Jpn. 1967, 40, 1920-1925. 